\title{
Tetralogy of Fallot with absent pulmonary valve: main differences with classic Fallot are crucial for an accurate prenatal diagnosis and counselling
}

\author{
Rita Ataíde Silva (1) , Duarte Martins 두 , Ana Teixeira, Rui Anjos
}

Paediatric Cardiology, Hospital de Santa Cruz, Carnaxide, Lisboa, Portugal

Correspondence to Dr Rita Ataíde Silva; ritataide@gmail.com

Accepted 26 March 2020

\section{DESCRIPTION}

Tetralogy of Fallot (TOF) is the most common cyanotic congenital heart disease. Classic features are a large perimembranous ventricular septal defect; aorta overriding the interventricular septum; right ventricular hypertrophy and right ventricular outflow tract obstruction (RVOTO) at subvalvar, valvar or supravalvar level and hypoplastic pulmonary arteries (PA), with variable severity.

A different and very rare form of TOF $(<3 \%$ of total cases) occurs with absent/dysplastic pulmonary valve (AVP) leaflets, often with a hypoplastic ring causing RVOTO. In this rare condition, prenatal images are pathognomonic, with pulmonary valve regurgitation, enlargement of pulmonary trunk and branches and usually absent ductus arteriosus. Prenatal diagnosis can differentiate both conditions, which is of utmost importance for counselling, as it permits scheduling childbirth in a tertiary centre with the support of paediatric cardiology and/or cardiothoracic surgery in the case of AVP. ${ }^{2}$ Prenatal management significantly improves the chances of survival and long-term results. ${ }^{3}$ Nevertheless, these cases remain highly difficult to predict, given the various degrees of involvement of the lung parenchyma, from mild bronchomalacia to severe dysplasia.

We present a case of TOF with AVP, diagnosed at 26 weeks' gestation with typical features of TOF, severe pulmonary valve regurgitation (video 1 and figure 1), significant dilatation of the pulmonary trunk and branches and absent ductus arteriosus. PA's dimensions remained stable during pregnancy. Investigation of $22 \mathrm{q} 11$ deletion was refused by the mother. Pregnancy was uneventful. Delivery occurred in a tertiary centre at 38 weeks gestation. Immediate severe respiratory distress with oxygen refractory hypoxemia resulted in invasive ventilation at $20 \mathrm{~min}$

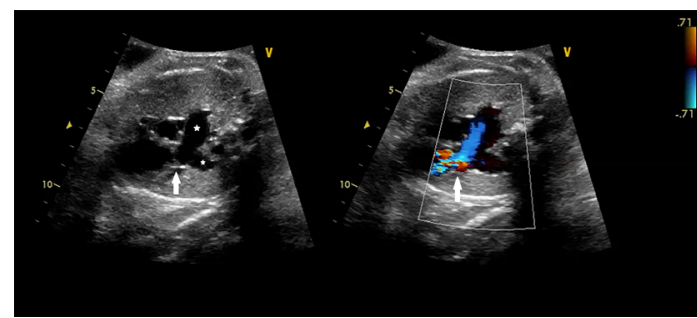

Figure 1 Fetal echocardiography 32 weeks' gestation: absent pulmonary valve (arrows) with significant regurgitation (blue coloured reverse flow) and severe dilatation of main pulmonary artery and its branches (stars).

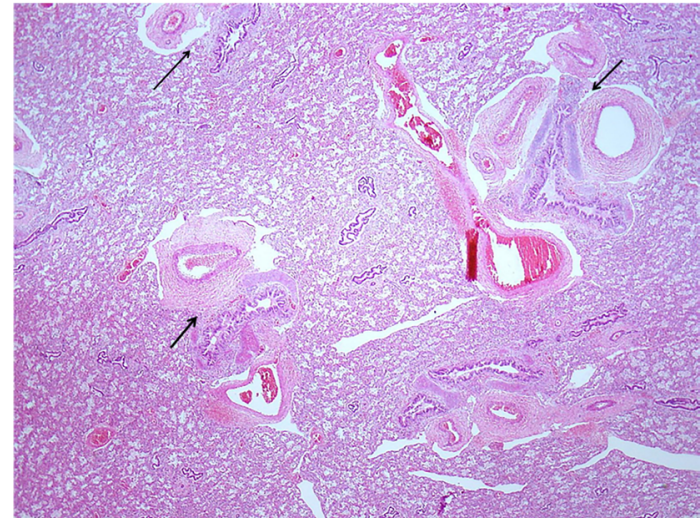

Figure 2 Histology postmortem: severe airway compression by thick vascular structures (arrows) severe bronchomalacia since embryonic life; it was excluded alveolar capillary dysplasia.

of life. Transthoracic echocardiogram showed exclusive right to left shunt in the absence of RVOTO. Pulmonary venous return anomalies were excluded. Ventilatory parameters were optimised and inhaled nitric oxide was initiated. After starting inotropic support with temporary improvement, there was an inexorable decline. Extracorporeal membrane oxygenation (ECMO) was considered but refused by a multidisciplinary team since the patient was very unstable, needed transport to another hospital and ECMO would not preclude a surgical correction. This marked instability was probably due to a severe parenchymal lung disorder.

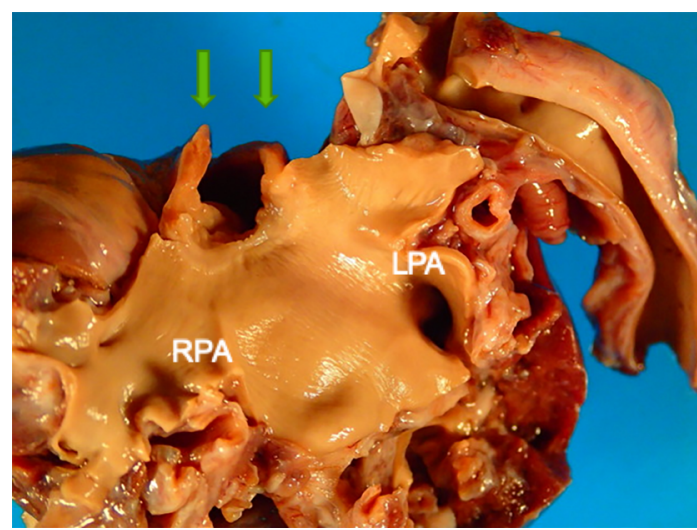

Figure 3 Absent pulmonary valve (green arrows) with severe dilatation of main pulmonary artery and its branches. LPA, left pulmonary artery; RPA, right pulmonary artery. 


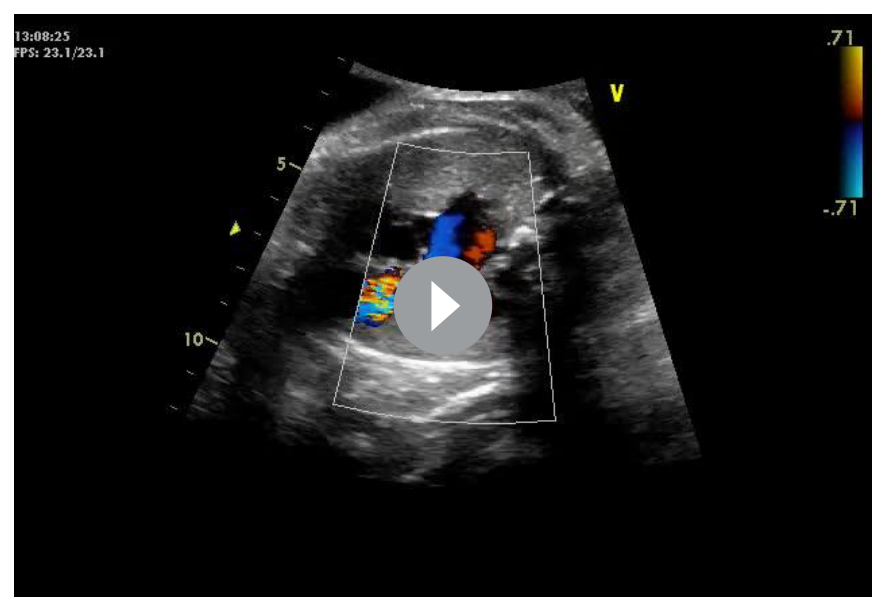

Video 1 Fetal echocardiography 32 weeks' gestation: absent pulmonary valve with significant regurgitation (blue coloured reverse flow) and severe dilatation of main pulmonary artery and its branches.

Death occurred at 26 hours of life. Autopsy confirmed the diagnosis and documented severe small airway respiratory involvement (figures 2 and 3).

Prenatal diagnosis of TOF with AVP can be made once we are aware of its particularities. Given the scarce literature about echocardiographic markers of pulmonary development and the incapability of evaluation of the impact of PA compression, parental counselling has to address every possibility, including the increased chances of success when the diagnosis is made antenatally. The delivery should take place in a tertiary hospital.

Although several series report good results with patients diagnosed prenatally, ${ }^{3}$ these patients generally have a much poorer prognosis than the classic form and the course of the disease is unpredictable. ${ }^{4}$ Professionals must be aware that there are no antenatal predictors of morbidity in this particular form of TOF. The high mortality is related to airflow obstruction caused by aneurysmal dilatation of the PA. ${ }^{25}$

Contributors All authors had contributed to manuscript composition: AT has followed this pregnancy as pediatric cardiologist. She captured several echocardiographic images during pregnancy, including figure 1 and video 1. DM and RA were member of the multidisciplinary team that took care of the newborn infant during his short period of life. RAS gathered all information and discussed the case with pathologists, providing image integration. All authors had read and corrected the manuscript.

\section{Patient's perspective}

As parents, we felt that we were given the clear notion that there were no prenatal echocardiographic markers that could anticipate or predict neonatal evolution being aware that this outcome would be possible.

\section{Learning points}

- Tetralogy of Fallot (TOF) with absent pulmonary valve is a rare variant of TOF, easy to diagnose, but hard to predict the outcome, with an overall poorer prognosis.

- There are currently no known definitive fetal markers of disease severity, therefore referral for programmed delivery at a tertiary centre with multidisciplinary neonatal support should be the standard of care for all cases.

- Even in the setting of the best neonatal conditions, parents should understand the risk of morbidity and mortality and the unpredictable evolution of each case.

Funding The authors have not declared a specific grant for this research from any funding agency in the public, commercial or not-for-profit sectors.

Competing interests None declared.

Patient consent for publication Parental/guardian consent obtained.

Provenance and peer review Not commissioned; externally peer reviewed.

\section{ORCID iDs}

Rita Ataíde Silva http://orcid.org/0000-0002-2090-0984

Duarte Martins http://orcid.org/0000-0003-0662-5629

\section{REFERENCES}

1 Tenisch E, Raboisson M-J, Rypens F, et al. Significance of lung anomalies in fetuses affected by tetralogy of Fallot with absent pulmonary valve syndrome. Cardiol Young 2017;27:1740-7.

2 Mivelaz Y, Lim KI, Templeton C, et al. Population based review of tetralogy of Fallot with absent pulmonary valve: is prenatal diagnosis really associated with a poor prognosis? Ultrasound Obstet Gynecol 2012;40:536-41.

3 Axt-Fliedner R, Kurkevych A, Slodki M, et al. Absent pulmonary valve syndrome diagnosis, associations, and outcome in 71 prenatally diagnosed cases. Prenat Diagn 2017:37:812-9.

4 Alsoufi B, Williams WG, Hua Z, et al. Surgical outcomes in the treatment of patients with tetralogy of Fallot and absent pulmonary valve. Eur J Cardiothorac Surg 2007:31:354-9.

5 Yong SMet al. Long term outcomes of patients with absent pulmonary valve syndrome: 38 years of experience, Society of thoracic surgeons. Elsevier, 2014.

Copyright 2020 BMJ Publishing Group. All rights reserved. For permission to reuse any of this content visit

https://www.bmj.com/company/products-services/rights-and-licensing/permissions/

BMJ Case Report Fellows may re-use this article for personal use and teaching without any further permission.

Become a Fellow of BMJ Case Reports today and you can:

- Submit as many cases as you like

- Enjoy fast sympathetic peer review and rapid publication of accepted articles

- Access all the published articles

- Re-use any of the published material for personal use and teaching without further permission

Customer Service

If you have any further queries about your subscription, please contact our customer services team on +44 (0) 2071111105 or via email at support@bmj.com.

Visit casereports.bmi.com for more articles like this and to become a Fellow 